1.2D Yildiz, ${ }^{2} Y$ Sanisoğlu. ' Gulhane Military Medical Academy; ${ }^{2}{ }^{2}$ ıldırım Beyazıt University, Faculty of Medicine, Ankara, Turkey

Objective This study is planned for quantification of validity and confidince of "What Being the Parent of a Baby is Like (WPL)" scale in Turkish women who have the first baby.

Material-Methods Study is composed by the 81 mothers who have the first baby. The scale, was created by Karen Pridham, administrated to the mothers at the end of 1st week, 1st month and 3rd month. A questionnarie of sociodemographic aspects of mothers and "What Being the Parent of a Baby is Like" scale were used for the collection of the datas.

Results Cronbach alfa coeeficients which were collected from the graphic rating scales are ranged between 10.13 and 82.07. All the subdimensions except the "Centrality" are appreciated that they have validity and confidince.

Conclusion The scale can be used for evaluation of a mother's, that has a new baby after laboring, quality at the same time it can be used as a guide for compliance for motherhood and entire dealing in Turkey.

\section{HOME CARE OF CHILDREN WITH FOP (FIBRODYSPLASIA OSSIFICANS PROGRESSIVA)}

doi:10.1136/archdischild-2012-302724.1877

${ }^{1} \mathrm{H}$ Kuwata, ${ }^{1} \mathrm{H}$ Soga, ${ }^{1} \mathrm{M}$ Shirasaka, ${ }^{1} \mathrm{Y}$ Komai, ${ }^{2} \mathrm{~K}$ Kuwata. 'Department of Clinical Nursing, Division of Pediatric Nursing, Shiga University of Medical Science, Otsu City; ${ }^{2}$ Center for Emerging Infectious Diseases, Gifu University, Gifu City, Japan

Background FOP (Fibrodysplasia Ossificans Progressiva) is a rare disease in which muscles in the body gradually replaced with bones. There is no therapeutic at this stage. Since population of FOP patients is small, home care methods are devised only individually. Objective The aim of this study is to investigate the actual situation of home care for FOP patients and to consider the possible nursing home care for FOP patients.

Methods Subjects were 10 FOP patients (1 male and 9 female) and their families. We interviewed them on the daily care of their childhood and analyzed the transcripts by qualitative descriptive study. For ethical consideration, we explained to the subjects about contents of this study and got the informed consents.

Results We found the categories of FOP patients of the actual situations as follows;

7 categories in infants; reduction in outdoor playing, progress by the physical damages, appearance peculiar to ossific symptoms etc.; 6 categories in schoolchildren; the decline in ADL restriction by ossification, distrust of others, acceptance of the rare disease, invention for improvement in QOL etc.; 9 categories in adolescence; the $\mathrm{ADL}$ decline by ossification, the deterioration of condition by ossification, care for the injury prevention, notification of the name of a disease, invention for QOL improvement, the decision to become independent, etc.

Conclusions FOP children are now dependent on their family, they hope to live their own life in future. It is critical for nursing care to consider the ways keep them from injury and infection.

\section{THE RELATIONSHIP BETWEEN GCS AND LENGTH OF PICU STAY}

doi:10.1136/archdischild-2012-302724.1878

J Nicholas, D White. Paediatrics, Cambridge University Hospitals NHS Foundation Trust, Cambridge, UK

Background Our PICU, admitting 700 patients a year is the major trauma centre for East Anglia, UK. The Glasgow Coma Score (GCS range 3-15) offers practitioners a guide to the critical patient's conscious level. We wanted to consider the relationship between the patients's GCS at the trauma scene with the length of time the children were admitted within the PICU.

Methods Exploratory data was collected reviewing 42 paediatric head-trauma patient's notes for two years, January 2010 - November 2011, to ascertain if any correlation could be established between the GCS scores at the scene and the length of the child's PICU stay (range 1-17 days).Children aged 0-16 where included (youngest 2 months, oldest 15 years), children who had suffered non-accidental injuries were excluded, as where those who had died.

Results The results showed a correlation of: lower the GCS the higher the length of PICU stay, however statistically ( $22=0.375)$, this could not be used to define all head injury admission length of stays, and other factors such as age may contribute.

Conclusions Emergency admissions effect the PICU's capability maintaining elective surgery, the ability to more accurate determine a patient length of stay is important in supporting work force planning, and supply purchasing. A lower GCS at the trauma scene did show some increased length of PICU admissions. The early GCS score could potentially offer a manager of a PICU an indication of the patient's estimated length of stay, a larger group and further research concerning other factors should be considered.

\section{PEDIATRIC NURSES KNOWLEDGE AND ATTITUDES TOWARD VITAL SIGNS}

doi:10.1136/archdischild-2012-302724.1879

${ }^{1} \mathrm{H}$ Yıldııım Sarı, ${ }^{2} \mathrm{~S}$ Çevik Yöntem, ${ }^{2} \mathrm{D}$ Demir, ${ }^{2} \mathrm{~N}$ Karaoğlan, ${ }^{2} \mathrm{~S}$ Şengün, ${ }^{3} \mathrm{~S}$ Çimen. ${ }^{1} / z m i r$ Katip Çelebi University Faculty of Health Science; ${ }^{2} \mathrm{Dr}$ Behcet Uz Çocuk Hastanesi, Izmir; ${ }^{3}$ Mevlana University Vocational School of Health Services, Konya, Turkey

Aim This study was planned to determine pediatric nurses' knowledge and attitudes towards monitoring the vital signs.

Methods One hundred eleven nurses working in the inpatient clinics at a children's hospital located in İzmir participated in the study. In the study, the following three forms were used: "The Socio-demographic Questionnaire", "The Vital Signs Knowledge Assessment Survey" and "The Vital Signs Attitude Assessment Survey". Knowledge and attitude surveys were prepared in accordance with the following guidelines published by the Royal College of Nursing: "Standards for Assessing, Measuring and Monitoring Vital Signs in Infants, Children and Young People" and "The Recognition and Assessment of Acute Pain in Children". Cronbach's alpha value of the Knowledge Survey is 0.87, the Attitude Survey is 0.86

Results The mean scores the nurses obtained from the knowledge survey were as follows: general principles: $87.9 \pm 7.8$, temperature: 87.6 \pm 10.1 , Pulse: $93.1 \pm 8.0$, respiration: $96.4 \pm 7.4$, blood pressure: $92.8 \pm 7.0$ and pain: $91.8 \pm 9.8$. The mean scores the nurses obtained from the attitude survey were as follows: general principles: $81.7 \pm 11.99$, temperature: $87.4 \pm 15.9$, pulse: $89.6 \pm 12.5$, respiration: $95.3 \pm 9.8$, blood pressure: $95.8 \pm 12.2$ and pain: $91.0 \pm 15.5$. Of the nurses, $49 \%$ stated that nurses themselves should decide about the frequency of monitoring vital signs whereas $41.4 \%$ stated that it should be ordered by the physician.

Conclusion According to our findings, nurses' knowledge and attitude scores relating to monitoring vital signs are quite high.

\section{FLUID, CALORIE AND PROTEIN INTAKE IN INFANTS BORN AT $<32$ WEEKS GESTATION - ARE WE MEETING THE STANDARDS?}

doi:10.1136/archdischild-2012-302724.1880

S Stones, S Gupta. Neonatology \& Paediatrics, University Hospital of North Tees, Stockton-on-Tees, UK

Background In premature infants optimal nutrition should be maintained and weight loss limited. Guidelines recommend 